
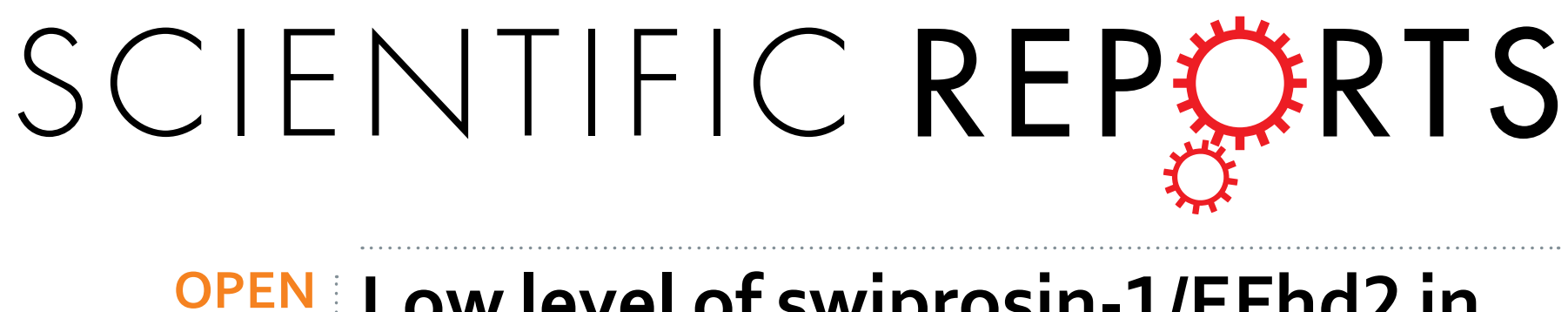

\title{
Low level of swiprosin-1/EFhd2 in vestibular nuclei of spontaneously hypersensitive motion sickness \\ mice
}

Received: 11 April 2016

Accepted: 14 December 2016

Published: 27 January 2017
Zhi-Bin Wang ${ }^{1,{ }^{*}}$, Ping Han ${ }^{1,{ }^{*}}$, Ling-Chang Tong ${ }^{1, *}$, Yi Luo ${ }^{2}$, Wei-Heng $\mathrm{Su}^{3}$, Xin Wei ${ }^{1}$, Xu-Hong Yu ${ }^{1}$, Wei-Ye Liu ${ }^{1}$, Xiu-Hua Zhang ${ }^{1}$, Hong Lei ${ }^{1}$, Zhen-Zhen $\mathrm{Li}^{1}$, Fang Wang ${ }^{2}$, Jian-Guo Chen ${ }^{2}$, Tong-Hui Ma ${ }^{3}$, Ding-Feng Su${ }^{1}$ \& Ling $\mathrm{Li}^{1}$

Susceptibility to motion sickness (MS) varies considerably among humans. However, the cause of such variation is unclear. Here, we used a classical genetic approach to obtain mouse strains highly sensitive and resistant to MS (SMS and RMS). Proteomics analysis revealed substantially lower swiprosin-1 expression in SMS mouse brains. Inducing MS via rotary stimulation decreased swiprosin-1 in the mouse brains. Swiprosin-1 knockout mice were much more sensitive to motion disturbance. Immunohistochemistry revealed strong swiprosin-1 expression in the vestibular nuclei (VN). Overexpressing swiprosin-1 in the VN of SMS mice decreased MS susceptibility. Down-regulating swiprosin-1 in the VN of RMS mice by RNAi increased MS susceptibility. Additional in vivo experiments revealed decreased swiprosin-1 expression by glutamate via the NMDA receptor. Glutamate increased neuronal excitability in SMS or swiprosin-1 knockout mice more prominently than in RMS or wild-type mice. These results indicate that swiprosin-1 in the VN is a critical determinant of the susceptibility to MS.

Motion sickness (MS) refers to a series of central and neuro-vegetative responses to the perception of motion, whether real or apparent ${ }^{1-3}$. Depending on the cause, MS is also referred to as sea sickness, car sickness, air sickness, space sickness or simulation sickness ${ }^{4,5}$. The symptoms typically follow a sequence from stomach discomfort and nausea to dizziness and vomiting ${ }^{6}$. Subjects with severe MS may even develop dehydration and electrolyte disturbances ${ }^{7,8}$. MS is a common problem, and almost anyone with a functional vestibular system can develop MS.

The vestibular system is critical for MS to occur. The primary functions of the vestibular system include spatial orientation and maintenance of balance ${ }^{4}$. Subjects with non-functioning labyrinths are immune to $\mathrm{MS}^{9}$. Bilateral vestibular neurectomy or labyrinthine ablation causes susceptible laboratory animals to become immune to $\mathrm{MS}^{3,10}$. In contrast, electrical vestibular stimulation can induce MS-like symptoms in human subjects ${ }^{11}$. The anatomy and function of the vestibular system have been well studied. First, hair cells with polarization vectors in the crista ampullaris membrane of the semicircular canals and the basilar membrane of the otolithic macula detect endolymph fluid motion relative to the bony structure and convert the mechanical motion to electrical signals ${ }^{12}$. Next, the vestibular nerve transmits electrical activity from the hair cells to the central vestibular nuclei (VN) of the brainstem. Vestibular afferents are active even at rest and are strikingly sensitive to head acceleration ${ }^{13,14}$. Finally, the VN processes vestibular afferent information and contacts with multiple nuclei and brain regions to form multiple vestibular nerve pathways ${ }^{13}$. Glutamate and acetylcholine are the main excitatory neurotransmitters both in vestibular afferent nerves and in the $\mathrm{VN}$ for transmitting excitatory nerve impulses ${ }^{15-17}$.

In contrast to our understanding of the anatomy involved in MS, the molecular mechanisms underlying MS development and the regulation of MS remain largely unknown. The development of anti-MS drugs are thus

${ }^{1}$ Department of Pharmacology, College of Pharmacy, Second Military Medical University, Shanghai 200433, China. ${ }^{2}$ Department of Pharmacology, Tongji Medical College, Huazhong University of Science and Technology, Wuhan, Hubei 430030, China. ${ }^{3}$ Basal medical College, Dalian Medical University, Dalian, Liaoning 130041, China. ${ }^{*}$ These authors contributed equally to this work. Correspondence and requests for materials should be addressed to J.-G.C. (email: chenjg0428@hotmail.com) orT.-H.M. (email: Math108@nenu.edu.cn) or L.L. (email: lingli_z163@163.com) 
a

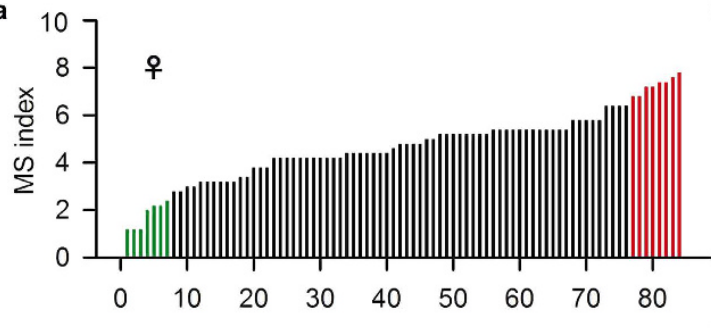

b

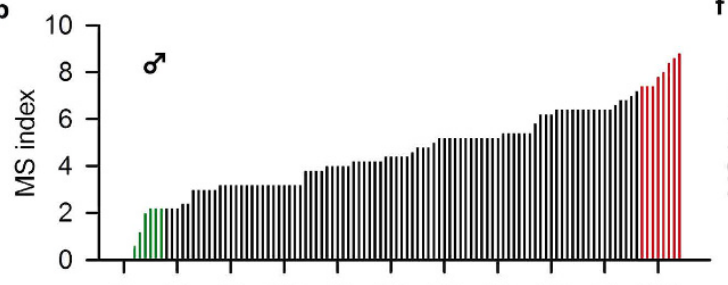

$\begin{array}{lllllllllll}0 & 10 & 20 & 30 & 40 & 50 & 60 & 70 & 80 & 90 & 100\end{array}$

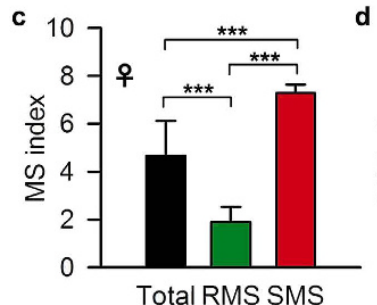

d

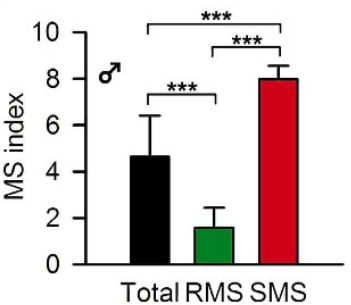

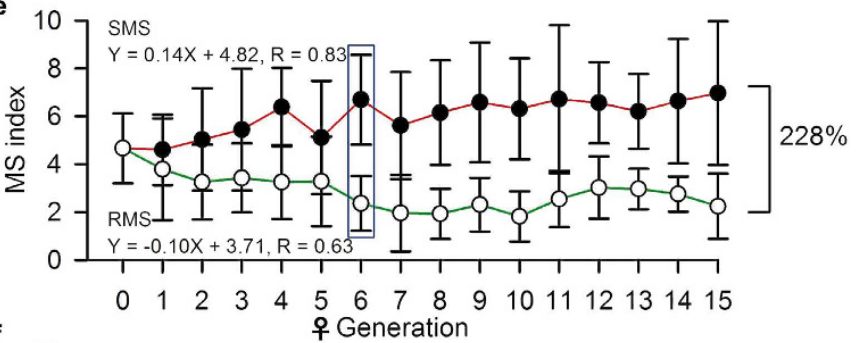

f 107 SMS

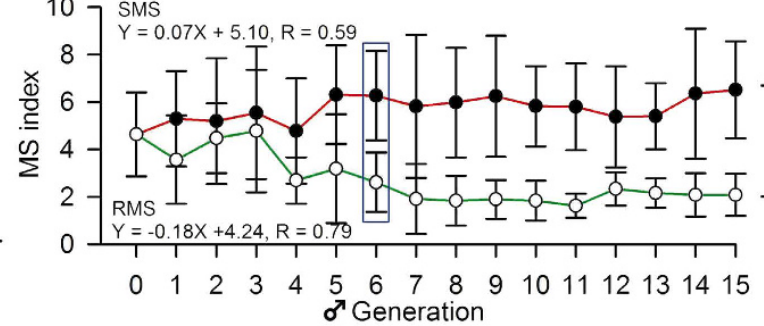

g

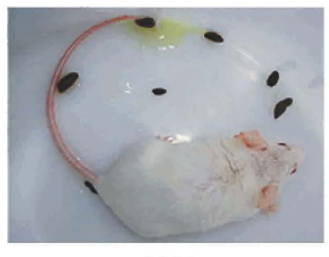

SMS

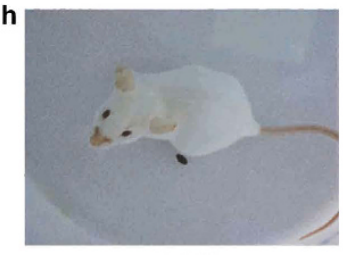

RMS

Figure 1. Establishment of two stable mouse strains spontaneously sensitive and resistant to MS. (a,b) The MS index in response to rotary stimulation for normal female and male Kunming mice. (c,d) The MS index in response to rotary stimulation for female and male mice highly sensitive (SMS) or resistant (RMS) to MS. (e,f) Separation of inherited strains that were SMS or RMS after fifteen generations of breeding guided by the MS phenotype. (g,h) Response of the sensitive (left) and resistant (right) strains to rotary stimulation-induced MS. The data are quantified as the mean $\pm \mathrm{SD}$. ${ }^{* *} \mathrm{p}<0.001$ compared to control or as indicated.

hindered. Scopolamine and dimenhydrinate are the main anti-MS drugs currently available. However, both agents are highly sedative due to general depression of the central nervous system.

Susceptibility to MS varies considerably across individuals ${ }^{4,18}$. It is expected that an in-depth understanding of the susceptibility to MS will be helpful in developing more specific treatments for MS. Abe et al. found that parents who are susceptible to MS are more likely to have children with higher sensitivities to MS. Moreover, twin studies demonstrated familial aggregation and significant heritability ${ }^{19,20}$. These findings highlight the importance of genetic factors in determining susceptibility to MS. In this regard, creating an animal model in which genetic factors are involved in MS would be of great value. The goal of the current study was to establish a genetic animal model that is hypersensitive to MS and to explore the possible factors governing MS susceptibility.

Mice lack a vomiting reflex ${ }^{21}$ but develop other symptoms typical of MS upon rotation: piloerection, tremble, and urinal and faecal incontinence. In a previous study, we used a score based on the symptoms mentioned above as an index to reflect the severity of MS in mice ${ }^{22}$. In the current study, we used selective breeding to obtain two mouse strains that were highly sensitive to MS (SMS) and resistant to MS (RMS). Proteomics studies revealed decreased expression of swiprosin-1, a protein selectively expressed in VN neurons, in SMS mice.

In the next set of experiments, we considered wild-type mice to further study swiprosin-1. The results demonstrated that swiprosin-1 level changes are specific in MS. Additionally, we found that swiprosin-1 is an anti-MS protein.

\section{Results}

Generation of RMS and SMS mice. In a previous study conducted in our laboratory, we noticed significant variations in the susceptibility to MS in mice, and the MS index was normally distributed ${ }^{22}$. To unravel the genetic basis of the varying susceptibility to MS, we obtained SMS and RMS strains by phenotype-guided breeding using genetically heterogeneous outbred mice as the founders (Fig. 1a,b). The MS index of the founders varied from 0 to 8.8 and did not differ between the female and male subjects ( $4.7 \pm 1.5$ vs. $4.6 \pm 1.8$, respectively) (Fig. 1c,d). The F0 generation included eight pairs of mice with low (green symbols) and high (red symbols) MS indexes ( $<2.0$ vs. $>7.0$, respectively).

MS susceptibility stably separated after selective breeding for six generations (Fig. 1e,f, blue rectangles). At the $15^{\text {th }}$ generation, the MS index was 7.0 \pm 3.0 in female SMS mice and $2.2 \pm 1.4$ in female RMS mice, with a difference of $228 \%$ (Fig. 1e). The MS index was $6.5 \pm 2.1$ in male SMS mice and $2.1 \pm 0.9$ in male RMS mice for a difference of $318 \%$ (Fig. 1f). The symptoms of MS after 40-min rotary stimulation were much more severe in 


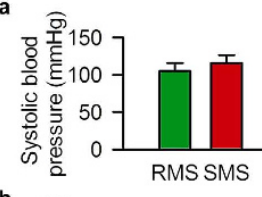

b

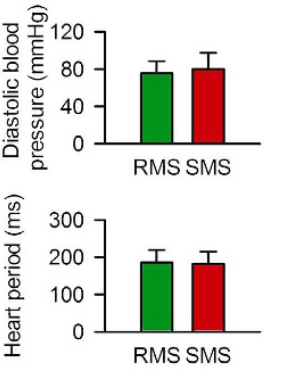

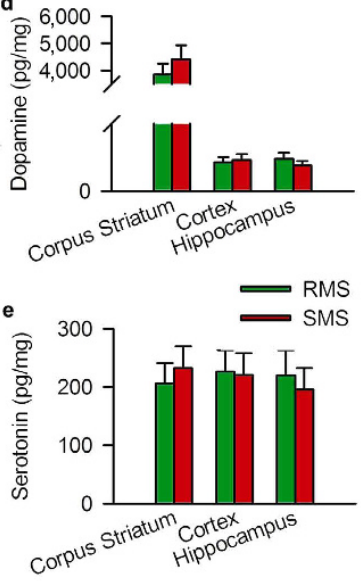

f

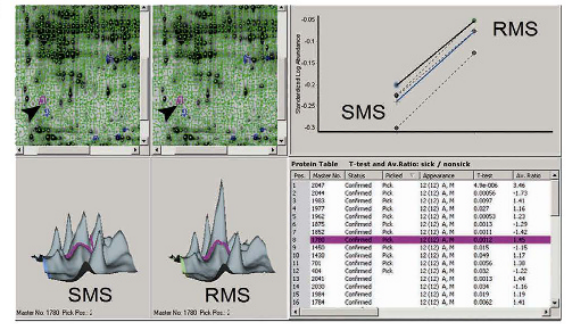

g

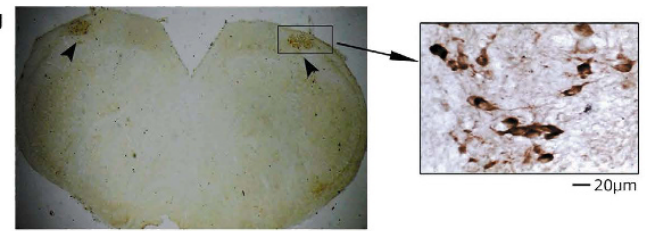

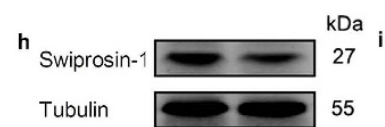

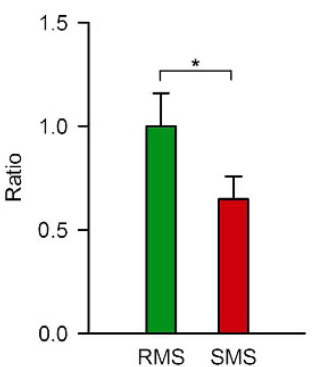

${ }_{\text {j }}^{\text {Swiprosin-1 }}$

Tubulin
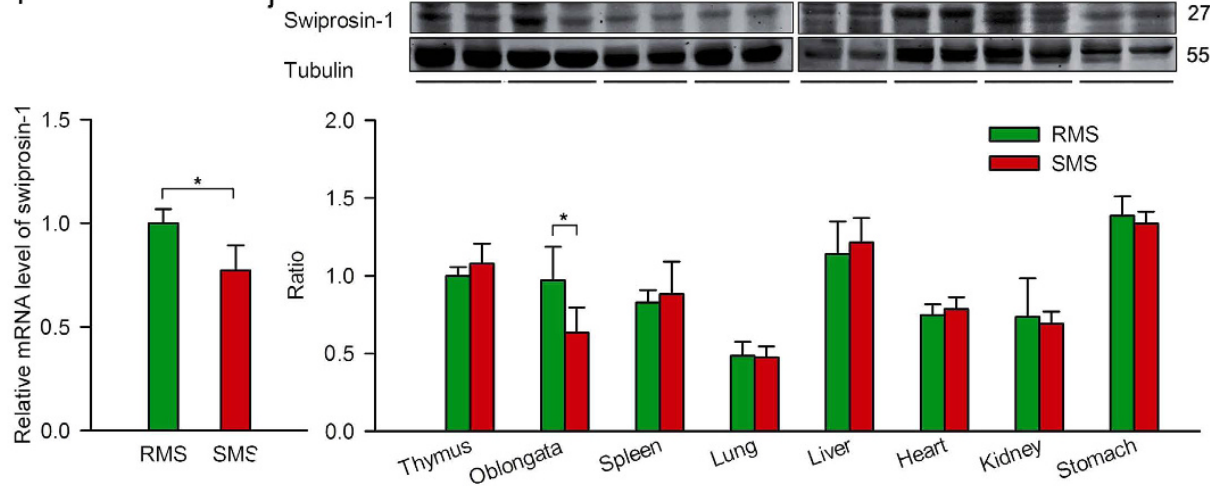

MS

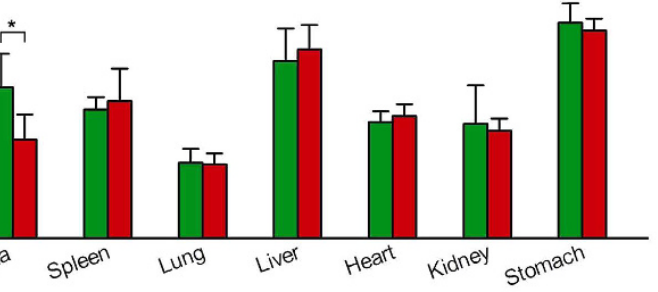

Figure 2. Different expression of swiprosin-1 in the VN of RMS and SMS mice. (a-c) Systolic blood pressure, diastolic blood pressure and heart period of RMS and SMS mice. (d,e) Dopamine and serotonin content in the corpus striatum, the cerebral cortex and the hippocampus of RMS and SMS mice. (f) Differential swiprosin-1 levels were identified between the brains of RMS and SMS mice by two-dimensional fluorescence difference gel electrophoresis analysis. (g) Localization of swiprosin-1 in the $\mathrm{VN}$ of the medulla oblongata of the mice by immunohistochemistry. (h) Differential swiprosin-1 level was confirmed in the brains between the RMS and SMS mice by Western blotting. (i) Swiprosin- 1 in different tissues of the RMS and SMS mice. Data are quantified as the mean $\pm S D$. ${ }^{*} \mathrm{p}<0.05$ compared to control or as indicated; $\mathrm{n}=3-8$ in each group.

the SMS mice than in the RMS mice (Fig. 1g,h). Thus, we successfully established two stable mouse strains: mice hypersensitive to MS and mice hyposensitive to MS.

Characteristics of SMS mice. Because the differences in MS index between the RMS and SMS mice were significant and persistent, mice from the $11^{\text {th }}$ generation were used for subsequent experiments. It is well known that the vestibular-autonomic nervous system and its control over the cardiovascular system and brain monoamines are implicated in $\mathrm{MS}^{23-25}$. We measured systolic blood pressure, diastolic blood pressure and the heart period (Fig. 2a,b and c) and determined the concentration of dopamine and serotonin in the cerebral cortex, the corpus striatum and the hippocampus (Fig. 2d,e), but we found no differences between the SMS and RMS mice.

To identify candidate proteins responsible for susceptibility to MS, we carried out a proteomics analysis of the brain in SMS vs. RMS mice. Mass spectrometry followed by bioinformatics analysis of cytosolic proteins in the brain of SMS $v s$. RMS revealed the following five differentially expressed proteins: swiprosin- 1 , aspartate- $\beta$-hydroxylase, mKIAA0106, glycolysis phosphoglycerate mutase 1 and peroxiredoxin-6 (Fig. 2f, Supplement 1). The differential expression of swiprosin-1 was most prominent as confirmed using Western blot and RT-PCR (Fig. 2h,i).

Swiprosin-1 was first identified in human lymphocytes, predominantly in $\mathrm{CD}^{8+}$ lymphocytes ${ }^{26}$ and later in immature, resting or activated $\mathrm{B}$ cells $\mathrm{s}^{27,28}$, mast cells ${ }^{29,30}$, human peripheral blood mononuclear cells ${ }^{31}$ and mouse platelets $^{32}$. Swiprosin-1 was also found in non-lymphoid tissue, especially in the brain ${ }^{33-35}$. Autonomic function is primarily controlled by the medulla oblongata in the lower brainstem ${ }^{36}$. Immunohistochemistry revealed strong swiprosin-1 expression in the VN (Fig. 2g), a brain region critical for MS ${ }^{37}$. Movement sensed by the semicircular canals and otolith organs is transmitted to the vestibular sensory cells (hair cells), which in turn transmit electrical signals via the VN to the oculomotor control areas, the cerebellum, and the spinal cord ${ }^{14}$. Swiprosin-1 expression did not differ between the SMS and RMS mice in the liver, heart, kidneys, stomach, thymus, spleen and lungs (Fig. 2j), suggesting the specificity of altered expression in the VN. 

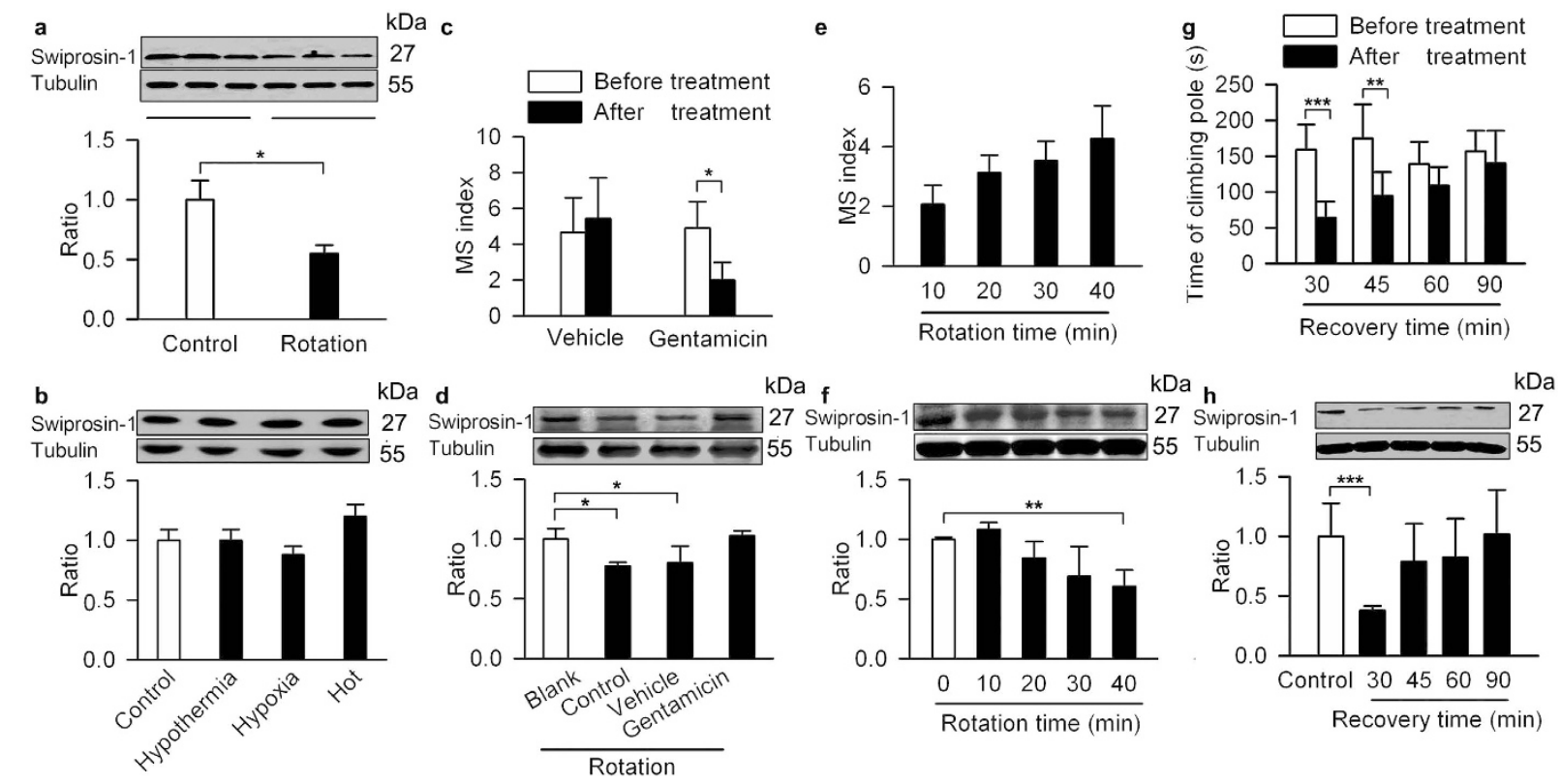

Figure 3. Selective response of swiprosin-1 to motion stimulus. Protein levels of swiprosin-1 were determined by Western blotting of the $\mathrm{VN}$ of mice that underwent with rotary stimulation (a), hypoxia, hypothermia and hyperthermia (b). The MS index (c) and swiprosin-1 level in the VN (d) after intratympanic injection of gentamicin and after undergoing rotary stimulation. The MS index (e) and swiprosin-1 levels in the VN (f) after rotation for different stimulation times. (g) Time of pole climbing at different time points after rotary stimulation. Behavioural recovery coincided with swiprosin-1 levels at different time point (h). Data quantified as the mean \pm SD. ${ }^{*} \mathrm{p}<0.05,{ }^{* *} \mathrm{p}<0.01,{ }^{* *} \mathrm{p}<0.001$ compared to control or as indicated; $\mathrm{n}=3-6$ in each group.

Selective response of swiprosin-1 to motion stimulus. To determine the change in swiprosin-1 after rotatory stimulus and the specificity of this change, we examined swiprosin-1 expression after rotation and under hypoxia, hypothermia and heat conditions. The result showed down-regulated swiprosin-1 in the VN after a 40-min rotation session (Fig. 3a) but not after other types of stressors, indicating that the swiprosin-1 response is specific to motion stimulus (Fig. 3b). Bilateral labyrinthectomy that eliminates vestibular afferent function prevents $\mathrm{MS}^{38}$. Gentamicin is an agent widely used for chemical labyrinthectomy ${ }^{39}$. Histological results showed that hair cells and Sertoli cells were nearly absent after chemical labyrinthectomy (Supplement 2). In our experiments, the mouse MS index was decreased 10 days after intratympanic injection of gentamicin (Fig. 3c). The down-regulation of swiprosin-1 after rotary stimulation was not seen after labyrinthectomy (Fig. 3d), suggesting that the response of swiprosin-1 to rotary stimulus requires the integrity of the vestibular system.

We noticed a temporal relationship between the swiprosin-1 level and the MS index along the development and dissipation of rotation-induced MS: the swiprosin-1 level gradually decreased, whereas the MS index gradually increased with prolonged rotation time (Fig. 3e,f). After the session, recovery of swiprosin-1 expression coincided with motor coordination recovery, as reflected by a pole-climbing test (Fig. 3g,h).

Swiprosin-1 influences the MS index. To further examine the function of swiprosin-1 in the VN, we constructed lentiviruses expressing siRNA of swiprosin-1 (LV-shRNA-Swi) or full-length swiprosin-1 (LV-Swi) (Fig. 4a,b). In wild-type control mice, stereotactic injection with LV-shRNA-Swi reduced the level of swiprosin-1 in the VN (Fig. 4c, left) and increased the MS index (Fig. 4d, left). Injection of LV-Swi into the VN (Fig. 4c, right) significantly decreased the MS index (Fig. 4d, right). Reducing swiprosin-1 in the VN of RMS mice (Fig. 4e, left) increased the MS index (Fig. 4f, left). Over-expressing swiprosin-1 in the VN of SMS mice (Fig. 4e, right) decreased the MS index (Fig. 4f, right). Habituation is a common characteristic of MS ${ }^{40}$. Repeated exposure to motion decreases susceptibility to MS. In the current study, over-expressing swiprosin-1 in the VN decreased the duration required for habituation from 10 to 6 days (Fig. 4g).

To further determine the function of swiprosin-1 in the susceptibility of MS, we generated mice lacking swiprosin-1 (swiprosin-1 $1^{-1-}$ mice; generated in this laboratory; Fig. 5a-e). Swiprosin-1 $1^{-1-}$ mice were more sensitive to rotation in comparison to wild-type mice (Fig. 5f). The MS index tapered to a stable level upon daily exposure to rotation over 10-14 days (Fig. 5g) in the wild-type control mice but not in the swiprosin- $1^{-1-}$ mice (Fig. 5g) or in the SMS mice (Supplement 3). In the VN of the swiprosin- $1^{+/+}$mice, swiprosin-1 recovered to the baseline level by day 14 (Fig. 5h), suggesting that the swiprosin-1 level in the VN is closely associated with habituation to MS. Additionally, we also verified the distribution and function of swiprosin-1 in cynomolgus monkeys, and the results were similar to that observed in mice (Supplement 4). 

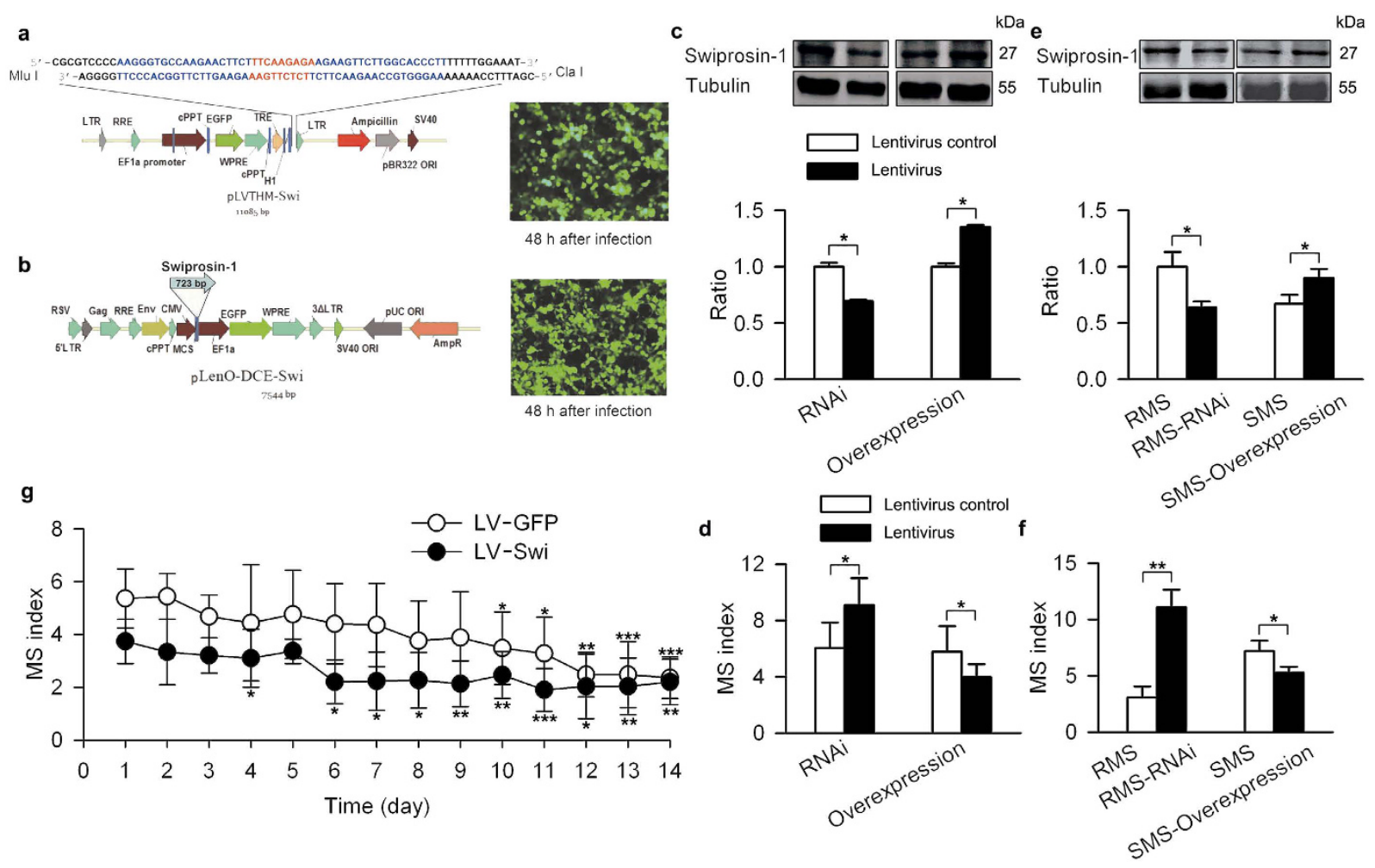

Figure 4. Contribution of swiprosin-1 level in the VN on mouse MS index. (a) Schematic diagram of LVshRNA-Swi (left) and infected $293 \mathrm{~T}$ cells (right). An interference sequence was inserted between the $M l u$ I and Cla I restriction sites and confirmed by DNA sequencing. (b) Schematic diagram of LV-Swi (left) and infected $293 \mathrm{~T}$ cells (right). Swiprosin-1 full-length coding sequence was inserted between the BamH I and Sal I restriction sites and confirmed by DNA sequencing. Swiprosin-1 level in the VN after injection of LVshRNA-Swi or LV-Swi into the VN of Kunming mice (c) and RMS and SMS mice (e). MS index after injection of LV-shRNA-Swi or LV-Swi into the VN of Kunming mice (d) and RMS and SMS mice (f). (g) MS index after injection of LV-GFP or LV-Swi in the VN of Kunming mice during the adaption period. Data were quantified as the mean \pm SD. ${ }^{\star} \mathrm{p}<0.05,{ }^{* *} \mathrm{p}<0.01,{ }^{\star * *} \mathrm{p}<0.001$ compared to control or as indicated; $\mathrm{n}=6-8$ in each group.

Glutamate down-regulates swiprosin-1. Decreased swiprosin-1 expression in response to rotation was prevented by prior injection of bortezomib into the VN to block proteasome-dependent protein degradation but not by injection of cycloheximide, which inhibits protein synthesis (Fig. 6a). We also found increased chymotrypsin-like protease activity after rotary stimulus (Fig. 6b), suggesting that the rapid decrease of swiprosin-1 is due to increased degradation but not reduced protein synthesis.

The activity of VN neurons could be influenced by many neurotransmitters, including acetylcholine, glutamate, and histamine $\mathrm{e}^{41,42}$. When these transmitters were applied in vivo to the $\mathrm{VN}$ in our experiments, only glutamate decreased swiprosin-1 (Fig. 6c). Glutamate is the main excitatory neurotransmitter of vestibular nerve afferents ${ }^{43}$. Vestibular afferent nerves release considerable amounts of glutamate to the vestibular nucleus upon stimulation $^{44}$. In vivo experiments showed that the NMDA receptor antagonist MK801 could prevent the reduction of swiprosin-1 levels and the chymotrypsin-like protease activity increase in the VN of mice after rotary stimulation (Fig. 6d,e). Stereotactic injection of MK801 into the VN also lowered the MS index of the mice (Fig. 6f).

Swiprosin-1 deficiency increases glutamate-induced excitation of the VN. To observe the effect of swiprosin-1 on neuronal excitability in the medial vestibular nucleus, the firing rate of neurons in swiprosin-1 knock out (KO) and wild type (WT) mice was recorded in brain slices in the presence or absence of glutamate. The results showed similar basal firing rates between the swiprosin-1 KO and WT mice (Fig. 7a). Upon incubation with $30 \mu \mathrm{M}$ glutamate for $1 \mathrm{~min}$, the firing frequency was higher in $\mathrm{KO}$ mice than in WT mice (Fig. 7b). Both MK801 and the $\alpha$-amino-3-hydroxy-5-methyl-4-isoxazolepro- pionic acid (AMPA) receptor antagonist CNQX decreased the firing rate in the presence of glutamate but only MK801 eliminated the difference in excitability between KO and WT mice (Fig. 7c,d). We also noticed higher firing rates in cultured VN neurons of SMS mice than in RMS mice in the presence of glutamate (Fig. 7f) but not in the absence of glutamate (Fig. 7e). The difference between the RMS and SMS mice was eliminated by administration of MK801 but not CNQX (Fig. 7g,h). 
a

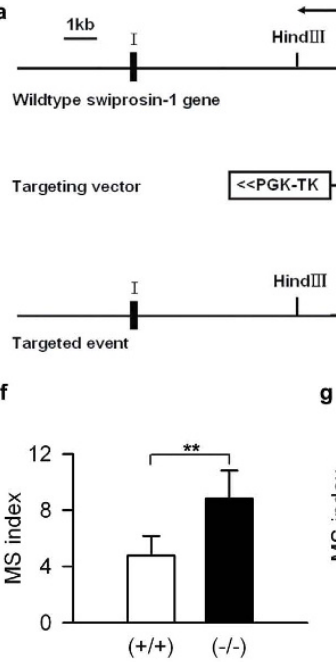

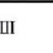
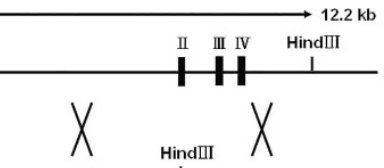

$\downarrow$
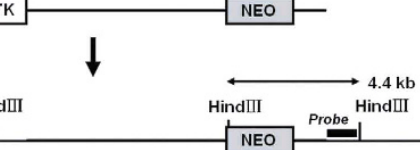

g

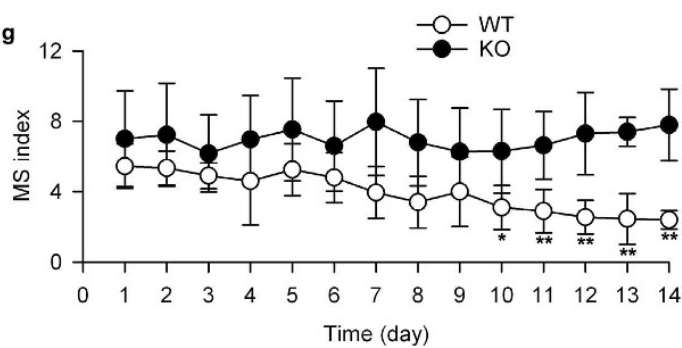

c

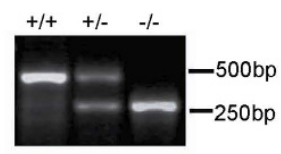

d $+++++--/-$
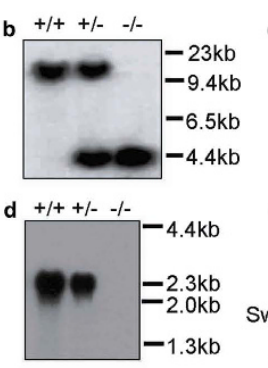

e

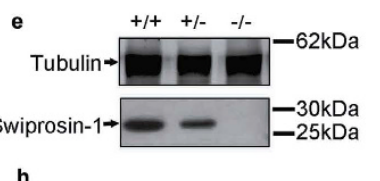

h

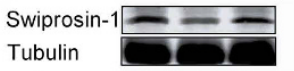

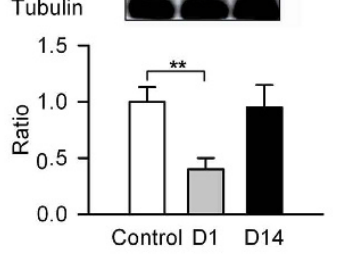

Figure 5. MS in swiprosin-1 knockout mice. (a) Gene targeting construct and endogenous swiprosin-1 locus. (b) Southern blot analysis of Hind3-digested mouse liver genomic DNA confirming the properly targeted swiprosin-1 gene locus. Probes used for Southern blotting analysis are shown by thick black bars in (a) along with the expected sizes of hybridized fragments, as indicated. (c) PCR genotyping of the swiprosin-1 allele. Predicted sizes of wild-type and null bands are $462 \mathrm{bp}$ and $263 \mathrm{bp}$, respectively. (d) Northern blot of mouse brain probed with a 500-bp fragment of the mouse swiprosin-1 $3^{\prime}$ coding sequence. (e) Immunoblots of mouse brains using tubulin and swiprosin- 1 antibodies. $+/+$, wild-type; $+/-$, heterozygous; and $-/-$, Swiprosin- 1 null. (f) MS index of wild-type (swiprosin-1 $1^{+/+}$) and homozygous (swiprosin-1 ${ }^{-/-}$) mice. (g) MS index of wild-type and swiprosin-1 knockout mice during the adaption period. (h) Swiprosin-1 level in the VN of wild-type mice on the first day and $14^{\text {th }}$ day of the adaption period. Data were quantified as the mean $\pm S D$. ${ }^{*} p<0.05$, ${ }^{\star *} p<0.01$ compared to control or as indicated; $n=6-8$ in each group.

\section{Discussion}

Swiprosin-1 was differentially expressed in the brains of two mouse strains with varying MS sensitivities (SMS and RMS). Functional studies indicated that swiprosin- 1 in the $\mathrm{VN}$ is a critical determinant of the susceptibility to MS.

An animal model with a spontaneous human disease is an ideal tool for studying the given disease. Currently, there are approximately 20 strains that simulate a number of human diseases, such as hypertension, diabetes and obesity in rodents, including in rats and mice ${ }^{45-47}$. These rodent models are typically obtained with classical inbreeding techniques after a directional screening for $10-20$ generations ${ }^{48}$. Recent studies point to a strong genetic predisposition of individuals to $\mathrm{MS}^{4,19}$. Considering the possible links between genetic basis and MS susceptibility, we first established two mouse strains (SMS and RMS mice). The separation of susceptibility to MS into two stable strains took only 6 generations, confirming strong influence by genetic factors.

The huge variation in MS index in the natural population of mice as described above (Fig. 1a,b) poses great difficulty in screening anti-MS drugs. The generation of the SMS mouse strain represents an important advancement and provides a platform for drug screening and for basic research. For example, with the help of genomics, proteomics and metabonomics, it is possible to find the gene(s), protein(s) or metabolite(s) responsible for differences in susceptibility.

Swiprosin-1 is a newly discovered protein with few known functional implications. It is also referred to as EF-hand domain-containing protein D2 (EFhd2) ${ }^{49}$. In immune cells, swiprosin-1 was found to be regulated by calcium signalling ${ }^{49,50}$, protein kinase $\mathrm{C}^{29,51,52}$, and nuclear factor- $\kappa \mathrm{B}^{29,51}$ and to be involved in apoptosis, actin bundling and polymerization ${ }^{53,54}$. It was also found to promote cell invasion and metastasis in cancer ${ }^{55}$. In the central nervous systems, swiprosin- 1 was recently found in neurites and synapses and identified to affect microtubule transport in neurons and to play a significant role in Alzheimer's disease and other neurological disorders ${ }^{56-58}$.

Proteomics, Western blot and RT-PCR analyses revealed lower expression of swiprosin-1 in SMS mouse brains than in RMS mouse brains. The significant down-regulation of swiprosin-1 at both the mRNA and protein levels in the VN of SMS mouse brains suggests that swiprosin-1 may be a genetic factor of susceptibility to MS. Although the concomitant down-regulation of swiprosin-1 mRNA and protein specifically in the VN of SMS mice suggests tissue-specific transcriptional mechanisms of swiprosin-1 gene regulation, additional post-translational mechanisms of swiprosin-1 regulation cannot be excluded. It also remains unclear whether the reduction in swiprosin-1 expression during MS is reversible, causative, compensatory or functionally irrelevant. However, our functional experiments indicated that swiprosin-1 is closely related to MS. The evidence supporting a specific relationship between swiprosin-1 and MS is summarized as follows: (1) Swiprosin-1 was detected at high levels in the cytoplasm of VN neurons, a brain region governing MS. (2) Swiprosin-1 levels in the VN decreased after rotation stimulus but were not changed by other stimuli, including hypoxia, hypothermia and heat. (3) Decreased swiprosin-1 levels after rotation stimulus required intact vestibular system. This decrease was abolished mice that 


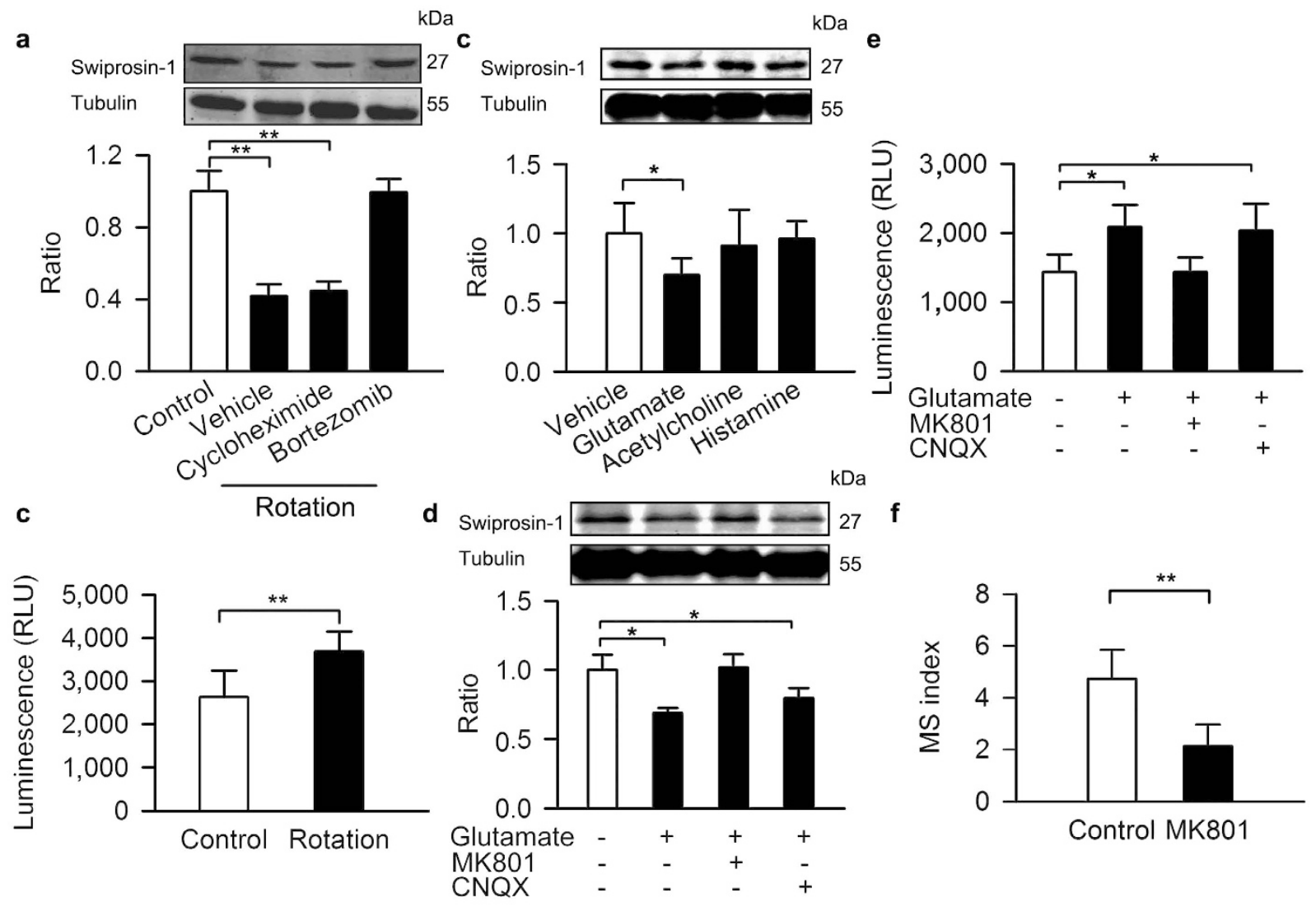

Figure 6. Glutamate down-regulates swiprosin-1 protein level in vivo. (a) Swiprosin-1 level in the VN after injection of bortezomib and cycloheximide in the VN of wild-type control mice after rotary stimulation. (b) Chymotrypsin-like protease activity of the VN after rotary stimulation. (c) Swiprosin-1 level in the VN after injection of neurotransmitters into the VN of wild-type control mice. Swiprosin-1 level (d) and chymotrypsinlike protease activity (e) in the VN after injection of glutamate, MK801 or CNQX into the VN of wild-type control mice. (f) MS index after injection of MK801 into the VN of wild-type control mice. Data were quantified as the mean $\pm S D .{ }^{*} \mathrm{p}<0.05,{ }^{\star *} \mathrm{p}<0.01$ compared to control or as indicated; $\mathrm{n}=6-8$ in each group.

were bilaterally labyrinthectomized with gentamicin. (4) Changes in swiprosin-1 levels in the VN are temporally associated with changes in the MS index. In addition, recovery of swiprosin-1 expression coincided with motor coordination recovery.

The decrease of swiprosin-1 after rotation is fairly rapid and does not seem to involve inhibition of gene expression. This notion was experimentally confirmed with cycloheximide, an inhibitor of protein synthesis: cycloheximide failed to prevent the decrease of swiprosin-1. In the contrary, decreased swiprosin-1 expression in response to rotation was prevented by bortezomib, which blocks proteasome-dependent protein degradation. We also found increased chymotrypsin-like protease activity after rotary stimulation, suggesting that the rapid decrease of swiprosin-1 is due to increased degradation and not reduced protein synthesis. This could also be supported by the identification of swiprosin- 1 as a putative ubiquitin substrate s $^{59}$.

Interestingly, swiprosin-1 gene expression was changed in $\mathrm{AD}$ patients ${ }^{33,57}$, Parkinson's patients ${ }^{60}$, schizophrenia patients ${ }^{61}$, and suicide victims ${ }^{62}$ and in a mouse model of amyotrophic lateral sclerosis/motor neuron disease $^{63}$. Collectively, these data suggest that swiprosin-1 gene expression is regulated in neurodegenerative diseases and psychiatric disorders ${ }^{58}$. However, little is known regarding the emerging role of swiprosin-1 in neurological disorders. Therefore, further studies are crucial for determining the roles of swiprosin-1 in the pathophysiology of motion sickness and neurological disorders.

To examine the function of swiprosin-1 in MS, we conducted a set of experiments using three different techniques. All the results indicated that swiprosin-1 is an anti-MS protein. First, lentiviruses expressing siRNA of swiprosin-1 (LV-shRNA-Swi) were used to down-regulate swiprosin-1 in the VN, and lentiviruses expressing full-length swiprosin-1 (LV-Swi) were used to over-express swiprosin-1 in the VN. In wild-type control mice, LV-shRNA-Swi increased the MS index, and LV-Swi decreased the MS index. More interestingly, over-expressing swiprosin-1 in the VN of SMS mice decreased the MS index, whereas reducing swiprosin-1 in the VN of RMS mice increased the MS index. Second, mice lacking swiprosin-1 (swiprosin-1 $1^{-1-}$ mice) were more sensitive to rotation in comparison to wild-type mice. Third, we conducted a set of electrophysiological experiments in brain slices. Glutamate is the main transmitter in the vestibular system. In microinjection experiments, the expression of swiprosin-1 was decreased by glutamate but not by histamine or acetylcholine. In addition, the NMDA receptor antagonist MK801 prevented the reduction in swiprosin-1 levels after rotation. Therefore, in this set of 
a
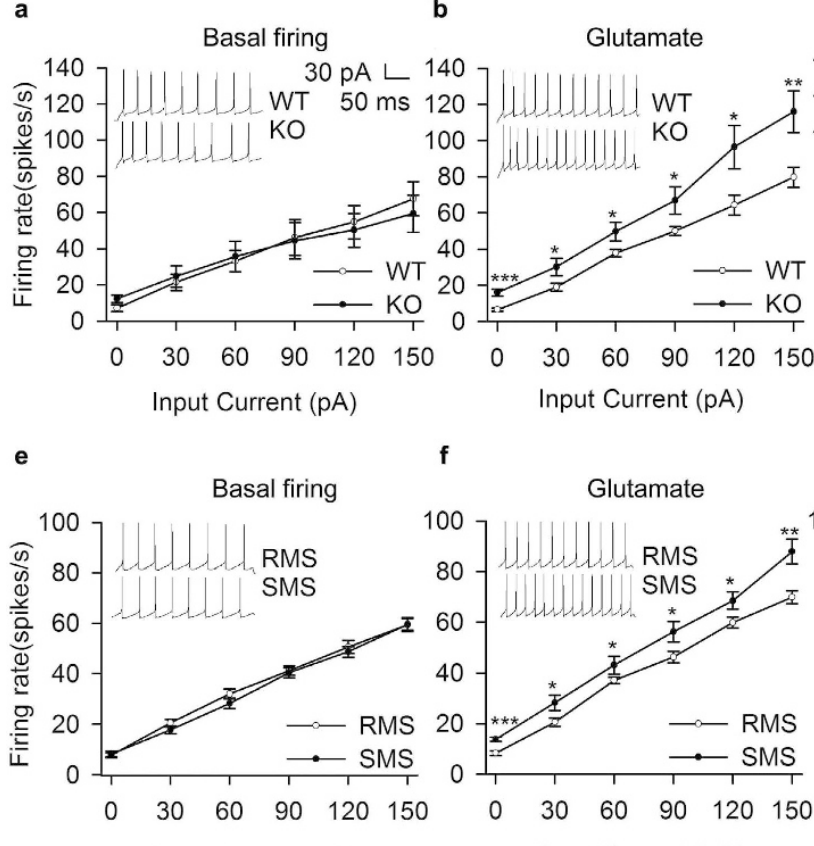

Input Current $(\mathrm{pA})$

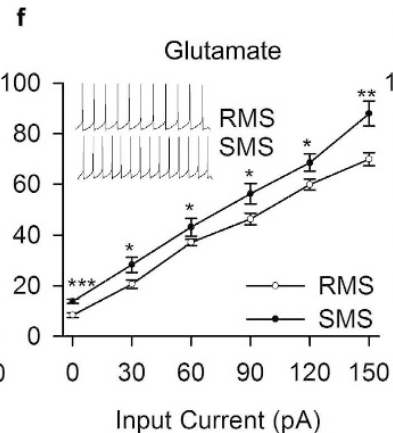

Input Current $(\mathrm{pA})$
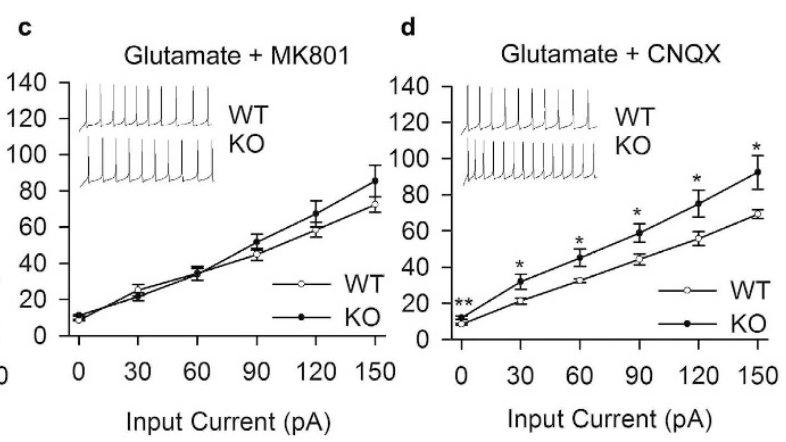

g

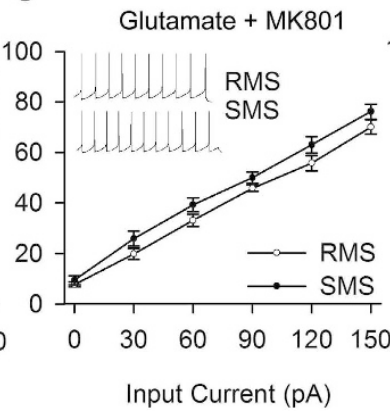

h

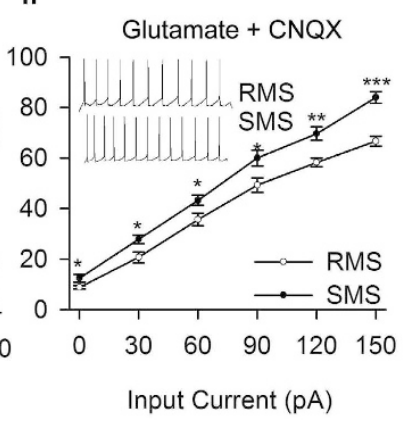

Figure 7. Electrophysiological study of swiprosin-1 on VN neuronal excitability in vitro. (a) Relationship between injected current and evoked firing rate of WT (open symbols) and KO (filled symbols) groups when no glutamate was applied. (b) Relationship between injected current and evoked firing rate of WT and KO groups during $30 \mu \mathrm{M}$ glutamate was applied. (c) Relationship between injected current and evoked firing rate of WT and KO during $20 \mu \mathrm{M}$ MK801 and $30 \mu \mathrm{M}$ glutamate were applied. (d) Relationship between injected current and evoked firing rate of WT and KO upon application of $20 \mu \mathrm{M} \mathrm{CNQX}$ and $30 \mu \mathrm{M}$ glutamate. (e) Relationship between injected current and evoked firing rate of RMS (open symbols) and SMS (filled symbols) groups when no glutamate was applied. (f) Relationship between injected current and evoked firing rate of RMS and SMS groups during $30 \mu \mathrm{M}$ glutamate was applied. (g) Relationship between injected current and evoked firing rate of RMS and SMS groups upon application of $20 \mu \mathrm{M}$ MK801 and $30 \mu \mathrm{M}$ glutamate. (h) Relationship between injected current and evoked firing rate of RMS and SMS groups upon application of $20 \mu \mathrm{M} \mathrm{CNQX}$ and $30 \mu \mathrm{M}$ glutamate. Representative traces of action potential elicited by $60 \mathrm{pA}$ depolarizing currents. Data were quantified as the mean \pm SEM. ${ }^{\star} \mathrm{p}<0.05,{ }^{* *} \mathrm{p}<0.01,{ }^{* * *} \mathrm{p}<0.001$ compared to control or as indicated; $\mathrm{n}=5-16$ in each group.

experiments, we selected glutamate as a stimulator of VN neuronal activity in brain slices to mimic the rotary stimulation in mice. The neuronal activity was enhanced by glutamate in brain slices obtained from either swiprosin-1 knockout mice or down-regulated mice (SMS) compared with their respective control. Evidently, the inhibition of swiprosin-1 on VN neuronal activity contributes to its anti-MS effect in vivo.

A recent study showed that deletion of the swiprosin-1 gene causes no detectable effect on brain anatomy or function ${ }^{56}$. Notably, vesicle transport velocity was enhanced in swiprosin-1 knockout primary hippocampal neurons and that swiprosin-1 inhibited microtubule gliding mediated by kinesin in vitro ${ }^{56}$. In recent studies, swiprosin-1 co-localized with neurite markers such as tau, microtubule-associated protein2 (MAP2), synapsin, and postsynaptic density 95 (PSD95) ${ }^{57}$, indicating that swiprosin-1 may play roles in both synapses and intracellular transport. The synaptic presence of swiprosin-1 was verified by biochemical analysis of isolated synaptosomes $^{56,57}$. Mielenz et al. speculated that loss of swiprosin-1 could modulate long-term potentiation by modulating the delivery of kinesin-transported cargo and by orchestrating local actin dynamics in a dynamic equilibrium $^{64}$. Given that swiprosin-1 is highly expressed in neurons of the VN and considering our results, it is possible that swiprosin-1 in VN neurons may play a role in synaptic plasticity and in the pathophysiology of motion sickness.

Habituation is a characteristic feature of MS. Desensitization has been reported to prevent MS in $>85 \%$ of the subjects $^{65}$. In our experiments, over-expressing swiprosin-1 in the VN shortened the adaptation time from 10 to 6 days. Consistent with this finding, habituation was not observed in the swiprosin-1 knockout mice.

Taken together, our data demonstrated that swiprosin-1 is a critical protein expressed in the VN that determined the susceptibility of mice to MS.

\section{Methods}

Animals. Mice (Kunming strain, outbred) weighing 18-22 g were provided by the Experimental Animal Center of the Second Military Medical University (Shanghai, China). During experiments, mice received humane care, and all mouse experiments were approved by the Second Military Medical University. All the experimental 
procedures were performed in accordance with the guidelines of the Second Military Medical University for the health and care of experimental animals.

A healthy adult male cynomolgus monkey weighing 3.5-4 kg was provided by the Suzhou Xishan Zhongke Drug R \& D Co., Ltd. (Suzhou, China). All the experiments performed in the cynomolgus monkey were approved by the Science and Technology Department of Jiangsu Province. All the experimental procedures were performed in accordance with the guidelines of the Science and Technology Department of Jiangsu Province regarding the health and care of experimental animals. The monkey was fixed in a rotary monkey chair, deviated from the centre axis of rotation by approximately $60 \mathrm{~cm}$. The rotational speed was $180^{\circ} / \mathrm{s}$ via clockwise rotation for $60 \mathrm{~s}$, followed by emergency stops, and then counter-clockwise rotation for $60 \mathrm{~s}$ lasting a total of $60 \mathrm{~min}$. The motion sickness symptoms in the cynomolgus monkey were scored according to evaluation criteria as described by Liu and Su60. Briefly, score = 1: lassitude (wryneck, eyes closed short), pale skin, licking lips, smacking, special position; score $=2$ : irritability, roaring, eyes closed more than 3 times in $1 \mathrm{~min}$ or eyes closed over $10 \mathrm{~s}$ for once; score $=4$ : urination, defecation; score $=8$ : nausea, retching; score $=16$ : vomiting. Scores were assessed six times and recorded at every 10-min interval. The highest score in one assessment was used if multiple symptoms occurred or if symptoms occurred several times. In addition, the final score was the sum of the six scores.

Rotational stimulation. Rotational stimulation was performed according to the procedure described by Ossenkopp with minor modifications ${ }^{66}$. Each mouse was enclosed in an individual hyaline centrifuge cage (length $=15 \mathrm{~cm}$, width $=15 \mathrm{~cm}$, and height $=25 \mathrm{~cm}$ ). The swing-arm on which the animal cage was suspended was mounted $60 \mathrm{~cm}$ from the axis of a turntable driven by a servo-controlled torque motor. The turntable had six swing-arms. The device began to rotate in the clockwise direction at a constant angular acceleration of $40^{\circ} / \mathrm{s}^{2}$. When the angular velocity reached $240 \%$, was slowed at a constant angular deceleration of $40 \% \mathrm{~s}^{2}$. Without pause, the device was rotated again in the counter-clockwise direction in the same manner. The swing frequency was $0.167 \mathrm{HZ}$, which was conducive to $\mathrm{MS}^{67,68}$. Mice were stimulated by rotating for $40 \mathrm{~min}$ and then placed on the ground for $5 \mathrm{~min}$. MS symptoms were observed and recorded. The score of MS symptoms was obtained according to the previously depicted evaluation criteria ${ }^{22}$. This score, defined as the MS index, is suitable for mice.

Lentiviral construction and preparation. The recombinant lentiviruses expressing the swiprosin-1 full-length coding sequence (LV-Swi) and the swiprosin-1 interference fragment (LV-shRNA-Swi) were produced by Shanghai Innovation Biotechnology Co. The viruses were concentrated by ultracentrifugation and titred by infection of confluent $293 \mathrm{~T}$ cells.

Stereotactic injection of lentivirus targeting the swiprosin-1 protein in the VN. Stereotactic manipulations were performed in 15 -week-old male mice to deliver $0.5 \mu \mathrm{L}$ purified virus $\left(2 \times 10^{10} \mathrm{Pfu} / \mathrm{mL}\right)$ LV-shRNA-Swi or LV-Swi to the $\mathrm{VN}$ at $(-6.5 \mathrm{~mm}$ posterior and $1.1 \mathrm{~mm}$ lateral to the bregma and $5 \mathrm{~mm}$ below the skull surface ${ }^{69}$. After 3 days, rotary stimulation was performed, and the medulla oblongata was harvested according to the approved procedure. Correct positioning of the $\mathrm{VN}$ was verified by injecting methylene blue (1\%) after the animals were sacrificed.

Generation of swiprosin-1-deficient mice. Recombineering was used to generate a gene targeting construct from a bacterial artificial chromosome (BAC) containing the swiprosin- 1 gene $(\mathrm{C} 57 \mathrm{Bl} / 6 \mathrm{~J}$ inbred strain). E14 ES cells were transfected with this construct, and successfully targeted ES cells were injected into $\mathrm{C} 57 \mathrm{Bl} / 6 \mathrm{~J}$ blastocysts. Mice bearing this targeted allele of exon 2-4 deletion in the germline were bred to generate swiprosin- $1^{-1-}$ mice.

Two-dimensional fluorescence difference gel electrophoresis. Protein extracts were prepared from mouse brain tissues as described previously ${ }^{70}$. Proteins were labelled using a CyDye DIGE Fluor minimal labelling kit (GE Healthcare) according to the manufacturer's instructions ${ }^{71}$. Briefly, Cy2 was used to label the pooled internal standard. Cy3 and Cy5 were used to randomly label the RMS and SMS samples. Following the labelling reaction, $50 \mu \mathrm{g}$ each of Cy2, Cy3 and Cy 5 labelled samples were mixed and diluted with rehydration buffer. For isoelectric focusing electrophoresis, the samples were placed in a strip holder using a step gradient protocol $(30 \mathrm{v}$ $6 \mathrm{hr}, 60 \mathrm{v} 6 \mathrm{hr}, 200 \mathrm{v} 1 \mathrm{hr}, 500 \mathrm{v} 1 \mathrm{hr}, 1000 \mathrm{v} 1 \mathrm{hr}$, and $8000 \mathrm{v} 6 \mathrm{hr}$ ). After the IPG strips were equilibrated in SDS equilibration solution, and the proteins were further separated on $12.5 \%$ homogeneous SDS-PAGE gels $(80 \mathrm{mV} / \mathrm{gel}$ for $20 \mathrm{~min}$ and $280 \mathrm{mV} / \mathrm{gel}$ for approximately $4 \mathrm{hr}$ ).

Scanning and image analysis. Cy2, Cy3, and Cy5 labelled images for each gel were scanned using a Typhoon Trio variable imager (GE Amersham). The ratios of the log-standardized protein spot abundances (differences in expression) between the groups were computed (One-way ANOVA, $\mathrm{p}<0.05$ ). Differentially expressed protein spots were excised from the post-stained gel for further identification.

Mass spectrometry and protein identification. The manually excised protein spots were digested with trypsin and then mixed with matrix solution for analysis using a 4700 MALDI-TOF/TOF Proteomics Analyzer (Applied Biosystems) according to the manufacturer's instructions ${ }^{72}$.

Immunostaining and blotting. The VN was dissected from mouse brainstems and homogenized in T-PER Tissue Protein Extraction Reagent (Pierce) supplemented with protease and phosphatase inhibitors (Merck). Samples were separated on an 8\% SDS PAGE and transferred to nitrocellulose membranes (Pall Corporation). The membranes were blocked with $5 \%$ bovine serum albumin and blotted with antibodies. Anti-swiprosin- 1 (IMGENEX) was used at a concentration of 1:2000, and anti-Tubulin (Beyotime) was used at 1:10000. Protein 
was visualized using IRDye-conjugated anti-mouse or anti-goat secondary antibodies at 1:5000. An Odyssey Infrared Imaging System (LI-COR) was used to analyses the results.

Each mouse was perfused with saline followed by formalin. The brains were fixed overnight at $4{ }^{\circ} \mathrm{C}$ in $4 \%$ paraformaldehyde and then treated in 30\% sucrose at room temperature for $1 \mathrm{hr}$. The brains were embedded in paraffin and resectioned into $20-\mu \mathrm{m}$-thick coronal sections (bregma $-0.8 \mathrm{~mm}$ to $-8 \mathrm{~mm}$ ). After deparaffination, endogenous peroxidase activity was blocked by incubating the sections in $1.5 \%$ peroxide in methanol for $20 \mathrm{~min}$. The sections were blocked in PBS containing $2 \%$ normal goat serum, $1 \% \mathrm{BSA}$, and $0.3 \%$ Triton X-100 and incubated in anti-swiprosin-1 antibody (IMGENEX) at 1:200 overnight at $4{ }^{\circ} \mathrm{C}$. Horseradish peroxidase (HRP)-labelled streptavidin and DAB were used to visualize each primary antibody.

RNA isolation and quantitative RT-PCR. Total RNA was extracted from the brainstem of the mice in each group with Trizol reagent according to the manufacturer's instructions. After reverse transcription, complementary DNA was used as templates for PCR. Primers for swiprosin-1 and an internal reference were as follows: swiprosin-1: forward, 5' -GTGTCCGTTGCTGTGTTGTG-3', reverse, 5' -CCCCTCCGATTCTCATAGG T-3'; GAPDH: forward, 5'-GTATGACTCCACTCACGGCAAA-3', reverse, 5'-GG TCTCGCTCCTGGAAGATG-3'. The housekeeping gene GAPDH was used as an internal control, and the amount of RNA was calculated by the comparative threshold cycle method as recommended by the manufacturer. Quantitative real-time PCR was carried out using an ABI 7500 real-time PCR system (Applied Biosystems, Foster, CA, USA).

Climbing pole test. Mice were evaluated for their performance on a vertical pole $(1 \mathrm{~cm}$ in diameter and $60 \mathrm{~cm}$ in height) after rotary stimulation. Each mouse was placed on a vertical pole and descended the pole with its head upward. The total time taken to descend three times was recorded.

MS habituation. Animals were subjected to rotatory stimulation as described above at the same time every day for 2 weeks. The MS index was carefully recorded.

Bilateral labyrinthectomy. Twenty male KM mice, each weighing $18-22 \mathrm{~g}$, were used for this study. The animals were divided into two groups ( $\mathrm{n}=10$ in each): I, control; II, Gentamicin (Zhong Xi Pharmaceutical Co., Ltd., Shanghai). Animals in group I received $50 \mu \mathrm{l}$ saline in each tympanic cavity; animals in group II received $50 \mu$ l gentamicin $(40 \mathrm{mg} / \mathrm{ml})$ in each tympanic cavity. After inducing anaesthesia, the solutions were injected into the right middle ear through a 1-ml injector in the lower posterior part of the tympanic membrane. After each injection, animals were kept in the left lateral decubitus position for five minutes under mild anaesthesia to minimize reflux of the applied drugs. The left side of the ear received the same operation. Ten days later, the animals underwent rotatory stimulation and then were killed to obtain the labyrinth and vestibular nucleus. MS index and samples were discarded if the results of labyrinth HE staining indicated failed labyrinthectomy.

Proteasome activity assay. Ice-cold PBS $(20 \mu \mathrm{l})$ containing $5 \mathrm{mM}$ EDTA (PBSE) was added to $1 \mathrm{mg}$ VN tissue and sonicated on ice for $20 \mathrm{~s}$ with a pulse length of $1 \mathrm{~s}$ two times using a pulsed homogenizer (JY92-II DN, SCIENTZ, China). The obtained tissue lysates were centrifuged at $13,000 \times g$ for $5 \mathrm{~min}$ at $4{ }^{\circ} \mathrm{C}$. The supernatants were diluted to a concentration of $0.2 \mu \mathrm{g} / \mu \mathrm{l}$ total protein with ice-cold PBSE. Then, $50 \mu \mathrm{l}$ corresponding to $10 \mu \mathrm{g}$ total protein was added to $50 \mu \mathrm{l}$ luminescent reagent containing the Ultra-Glo Luciferase and the signal peptide (Suc-LLVY-aminoluciferin) coupled to luciferin. After mixing the components and preincubating $60 \mathrm{~min}$ in a white 96-well plate at room temperature, the resulting luminescence was measured with an integration time of $1 \mathrm{~s}$ using a Multimode Reader (Infinite M200, TECAN) in luminometry mode ${ }^{73}$.

Electrophysiology. Briefly, brains from 14- to 21-day-old mice were rapidly removed, and coronal brain slices containing the vestibular nuclei were cut using a vibrating blade microtome in ice-cold artificial cerebrospinal fluid that was bubbled continuously with $95 \% \mathrm{O}_{2}-5 \% \mathrm{CO}_{2}$ and adjusted $\mathrm{pH}$ to 7.4 . After $1.5 \mathrm{~h}$ recovery at room temperature, an individual slice was transferred to a submerged recording chamber and continuously superfused with oxygenated artificial cerebrospinal fluid at $24-26^{\circ} \mathrm{C}$ at a rate of $3 \mathrm{ml} / \mathrm{min}$. Slices were supplemented with bicuculline $(20 \mu \mathrm{M})$ to block GABAergic neurotransmission. Neurons in the MVN were visualized with differential interference contrast optics under infrared illumination. Neurons were patched in whole-cell, current-clamp mode using an Axon clamp 700B amplifier. The membrane potential was sampled at $1 \mathrm{kHz}$ to continuously measure the firing rate; $20-40 \mathrm{kHz}$ sampling was used for all other measurements. Pipet and access resistances were bridge balanced throughout each experiment. Patch pipettes (4-8M $\Omega$ ) were filled with a solution containing the following: $135 \mathrm{mM}$ potassium gluconate, $2 \mathrm{mM} \mathrm{MgCl}_{2}, 0.1 \mathrm{mM} \mathrm{CaCl}, 1 \mathrm{mM} \mathrm{EGTA}, 10 \mathrm{mM}$ HEPES, and $2 \mathrm{mM} \mathrm{Na} 2 \mathrm{ATP}$ (pH 7.2, $285 \mathrm{mOsm}$ ).

Statistical Methods. The data were expressed as the mean $\pm S D$ or mean \pm SEM. Comparisons of parameters among two groups were made by unpaired Student's t-tests. Data involving more than two groups were assessed by analysis of variance (ANOVA).

\section{References}

1. Gay, L. N. \& Carliner, P. E. The Prevention and Treatment of Motion Sickness I. Seasickness. Science 109, 359, doi: 109/2832/359 10.1126/science.109.2832.359 (1949).

2. Cowings, P. S., Suter, S., Toscano, W. B., Kamiya, J. \& Naifeh, K. General autonomic components of motion sickness. Psychophysiology 23, 542-551 (1986).

3. Reason, J. T. B. J. J. Motion Sickness (Academic Press, 1975).

4. Golding, J. F. Motion sickness susceptibility. Autonomic neuroscience: basic \& clinical 129, 67-76, doi: 10.1016/j.autneu.2006.07.019 (2006). 
5. Muth, E. R. Motion and space sickness: intestinal and autonomic correlates. Autonomic neuroscience: basic \& clinical 129, 58-66, doi: 10.1016/j.autneu.2006.07.020 (2006).

6. Shupak, A. \& Gordon, C. R. Motion sickness: advances in pathogenesis, prediction, prevention, and treatment. Aviation, space, and environmental medicine 77, 1213-1223 (2006).

7. Landolt, J. P. \& Monaco, C. Seasickness in totally-enclosed motor-propelled survival craft: remedial measures. Aviat Space Environ Med 63, 219-225 (1992).

8. Sapegin, I. D. Effects of pikamilon on the brain water-electrolyte balance and in models of responses to the noise and vibration exposure, and their combination with motion sickness. Eksperimental'naia i klinicheskaia farmakologiia 63, 72-75 (2000).

9. Kennedy, R. S., Graybiel, A., McDonough, R. C. \& Beckwith, F. D. Symptomatology under storm conditions in the North Atlantic in control subjects and in persons with bilateral labyrinthine defects. Acta Otolaryngol 66, 533-540 (1968).

10. Crampton, G. H. Motion and space sickness (CRC Press, 1990).

11. Severac, A. Electrical vestibular stimulation and space motion sickness. Acta Astronaut 28, 401-408 (1992).

12. Goldberg, J. M. \& Fernandez, C. Vestibular mechanisms. Annu Rev Physiol 37, 129-162, doi: 10.1146/annurev.ph.37.030175.001021 (1975).

13. Rutka, J. A. Physiology of the Vestibular System. In Roland, P. S. \& Rutka, J. A. eds. Ototoxicity 20-27, Lewiston, New York, USA, BC Decker, Hamilton, Ont (2004).

14. Angelaki, D. E. \& Cullen, K. E. Vestibular system: the many facets of a multimodal sense. Annual review of neuroscience 31, 125-150, doi: 10.1146/annurev.neuro.31.060407.125555 (2008).

15. Harper, A. et al. Immunocytochemical localization of aspartate and glutamate in the peripheral vestibular system. Hearing research 86, 171-182 (1995)

16. de Waele, C., Muhlethaler, M. \& Vidal, P. P. Neurochemistry of the central vestibular pathways. Brain research reviews 20, 24-46 (1995).

17. Zanni, M., Giardino, L., Toschi, L., Galetti, G. \& Calza, L. Distribution of neurotransmitters, neuropeptides, and receptors in the vestibular nuclei complex of the rat: an immunocytochemical, in situ hybridization and quantitative receptor autoradiographic study. Brain Res Bull 36, 443-452, doi: 0361923094001935 (1995).

18. Abe, K., Oda, N. \& Hatta, H. Behavioural genetics of early childhood: fears, restlessness, motion sickness and enuresis. Acta geneticae medicae et gemellologiae 33, 303-306 (1984).

19. Reavley, C. M., Golding, J. F., Cherkas, L. F., Spector, T. D. \& MacGregor, A. J. Genetic influences on motion sickness susceptibility in adult women: a classical twin study. Aviation, space, and environmental medicine 77, 1148-1152 (2006).

20. Buyuklu, F., Tarhan, E. \& Ozluoglu, L. Vestibular functions in motion sickness susceptible individuals. Eur Arch Otorhinolaryngol 266, 1365-1371, doi: 10.1007/s00405-009-0927-6 (2009).

21. Montedonico, S. et al. Muscular architecture and manometric image of gastroesophageal barrier in the rat. Dig Dis Sci 44, 2449-2455 (1999).

22. Yu, X. H., Cai, G. J., Liu, A. J., Chu, Z. X. \& Su, D. F. A novel animal model for motion sickness and its first application in rodents. Physiology \& behavior 92, 702-707, doi: 10.1016/j.physbeh.2007.05.067 (2007).

23. Eiken, O., Tipton, M. J., Kolegard, R., Lindborg, B. \& Mekjavic, I. B. Motion sickness decreases arterial pressure and therefore acceleration tolerance. Aviat Space Environ Med 76, 541-546 (2005).

24. Yates, B. J. Autonomic reaction to vestibular damage. Otolaryngol Head Neck Surg 119, 106-112, doi: S0194599898002198 (1998).

25. Nishiike, S. Vestibular input to brain monoamine neurons-a review. Arch Ital Biol 141, $27-37$ (2003)

26. Vuadens, F. et al. Identification of swiprosin 1 in human lymphocytes. Proteomics 4, 2216-2220, doi: 10.1002/pmic.200300779 (2004).

27. Mielenz, D. et al. Lipid rafts associate with intracellular B cell receptors and exhibit a B cell stage-specific protein composition. Journal of immunology 174, 3508-3517 (2005).

28. Avramidou, A. et al. The novel adaptor protein Swiprosin-1 enhances BCR signals and contributes to BCR-induced apoptosis. Cell death and differentiation 14, 1936-1947, doi: 10.1038/sj.cdd.4402206 (2007).

29. Thylur, R. P. et al. Swiprosin-1 is expressed in mast cells and up-regulated through the protein kinase C beta I/eta pathway. Journal of cellular biochemistry 108, 705-715, doi: 10.1002/jcb.22307 (2009).

30. Ramesh, T. P., Kim, Y. D., Kwon, M. S., Jun, C. D. \& Kim, S. W. Swiprosin-1 Regulates Cytokine Expression of Human Mast Cell Line HMC-1 through Actin Remodeling. Immune network 9, 274-284, doi: 10.4110/in.2009.9.6.274 (2009).

31. Brachs, S. et al. Monoclonal antibodies to discriminate the EF hand containing calcium binding adaptor proteins EFhd1 and EFhd2. Monoclonal antibodies in immunodiagnosis and immunotherapy 32, 237-245, doi: 10.1089/mab.2013.0014 (2013).

32. Morowski, M., Brachs, S., Mielenz, D., Nieswandt, B. \& Dutting, S. The adaptor protein Swiprosin-1/EFhd2 is dispensable for platelet function in mice. PloS one 9, e107139, doi: 10.1371/journal.pone.0107139 (2014).

33. Vega, I. E. et al. A novel calcium-binding protein is associated with tau proteins in tauopathy. Journal of neurochemistry 106, 96-106, doi: 10.1111/j.1471-4159.2008.05339.x (2008).

34. Ferrer-Acosta, Y., Rodriguez Cruz, E. N., Vaquer Adel, C. \& Vega, I. E. Functional and structural analysis of the conserved EFhd2 protein. Protein and peptide letters 20, 573-583 (2013).

35. Ferrer-Acosta, Y. et al. EFhd2 is a novel amyloid protein associated with pathological tau in Alzheimer's disease. Journal of neurochemistry 125, 921-931, doi: 10.1111/jnc.12155 (2013).

36. Hornby, P. J. Central neurocircuitry associated with emesis. Am J Med 111 Suppl 8A, 106S-112S, doi: S000293430100849X (2001).

37. Marcus, D. A., Furman, J. M. \& Balaban, C. D. Motion sickness in migraine sufferers. Expert Opin Pharmacother 6, 2691-2697, doi: 10.1517/14656566.6.15.2691 (2005)

38. Kasri, M., Picquet, F. \& Falempin, M. Effects of unilateral and bilateral labyrinthectomy on rat postural muscle properties: the soleus. Exp Neurol 185, 143-153, doi: S0014488603004527 (2004).

39. Kobayashi, M. et al. Comparisons of cochleotoxicity among three gentamicin compounds following intratympanic application. Acta Otolaryngol 128, 245-249, doi: 10.1080/00016480701558948 787737849 (2008).

40. Tal, D., Bar, R., Nachum, Z., Gil, A. \& Shupak, A. Postural dynamics and habituation to seasickness. Neurosci Lett 479, 134-137, doi: 10.1016/j.neulet.2010.05.044 S0304-3940(10)00629-4 (2010).

41. Horii, A. et al. Effects of vestibular stimulation on acetylcholine release from rat hippocampus: an in vivo microdialysis study. J Neurophysiol 72, 605-611 (1994).

42. Horii, A. et al. Vestibular modulation of the septo-hippocampal cholinergic system of rats. Acta oto-laryngologica. Supplementum 520 Pt 2, 395-398 (1995).

43. Sasa, M., Takeshita, S., Amano, T. \& Kurisu, K. Primary neurotransmitters and regulatory substances onto vestibular nucleus neurons. Uchu Seibutsu Kagaku 15, 371-374 (2001).

44. Yamanaka, T., Sasa, M. \& Matsunaga, T. Release of glutamate from the vestibular nerve in the medial vestibular nucleus as a neurotransmitter: in vivo microdialysis study. Acta Otolaryngol Suppl 520 Pt 1, 92-93 (1995).

45. Okamoto, K. \& Aoki, K. Development of a strain of spontaneously hypertensive rats. Jpn Circ J 27, 282-293 (1963).

46. Makino, S. et al. Breeding of a non-obese, diabetic strain of mice. Jikken Dobutsu 29, 1-13 (1980).

47. Koletsky, S. Obese spontaneously hypertensive rats-a model for study of atherosclerosis. Exp Mol Pathol 19, 53-60, doi: 00144800(73)90040-3 (1973). 
48. Wisloff, U. et al. Cardiovascular risk factors emerge after artificial selection for low aerobic capacity. Science 307, 418-420, doi: 307/5708/418 10.1126/science.1108177 (2005).

49. Dutting, S., Brachs, S. \& Mielenz, D. Fraternal twins: Swiprosin-1/EFhd2 and Swiprosin-2/EFhd1, two homologous EF-hand containing calcium binding adaptor proteins with distinct functions. Cell communication and signaling: CCS 9, 2, doi: 10.1186/1478811X-9-2 (2011).

50. Hagen, S. et al. The B cell receptor-induced calcium flux involves a calcium mediated positive feedback loop. Cell Calcium 51, 411-417, doi: 10.1016/j.ceca.2012.01.004 S0143-4160(12)00013-9 (2012).

51. Kim, Y. D. et al. Swiprosin-1 Expression Is Up-Regulated through Protein Kinase C-theta and NF-kappaB Pathway in T Cells. Immune Netw 13, 55-62, doi: 10.4110/in.2013.13.2.55 (2013).

52. Kroczek, C. et al. Swiprosin-1/EFhd2 controls B cell receptor signaling through the assembly of the B cell receptor, Syk, and phospholipase C gamma2 in membrane rafts. Journal of immunology 184, 3665-3676, doi: 10.4049/jimmunol.0903642 (2010).

53. Kwon, M. S. et al. Swiprosin-1 is a novel actin bundling protein that regulates cell spreading and migration. PLoS One 8, e71626, doi: 10.1371/journal.pone.0071626 PONE-D-13-12698 (2013).

54. Huh, Y. H. et al. Swiprosin-1 modulates actin dynamics by regulating the F-actin accessibility to cofilin. Cell Mol Life Sci 70, 4841-4854, doi: 10.1007/s00018-013-1447-5 (2013).

55. Huh, Y. H. et al. Swiprosin-1 stimulates cancer invasion and metastasis by increasing the Rho family of GTPase signaling. Oncotarget 6, 13060-13071, doi: 10.18632/oncotarget.3637 (2015).

56. Purohit, P. et al. The Ca2+ sensor protein swiprosin-1/EFhd2 is present in neurites and involved in kinesin-mediated transport in neurons. PloS one 9, e103976, doi: 10.1371/journal.pone.0103976 (2014).

57. Borger, E., Herrmann, A., Mann, D. A., Spires-Jones, T. \& Gunn-Moore, F. The calcium-binding protein EFhd2 modulates synapse formation in vitro and is linked to human dementia. Journal of neuropathology and experimental neurology 73, 1166-1182, doi: 10.1097/NEN.0000000000000138 (2014).

58. Vega, I. E. EFhd2, a Protein Linked to Alzheimer's Disease and Other Neurological Disorders. Frontiers in neuroscience 10, 150, doi: 10.3389/fnins.2016.00150 (2016).

59. Danielsen, J. M. et al. Mass spectrometric analysis of lysine ubiquitylation reveals promiscuity at site level. Molecular \& cellular proteomics: MCP 10, M110 003590, doi: 10.1074/mcp.M110.003590 (2011).

60. Liscovitch, N. \& French, L. Differential Co-Expression between alpha-Synuclein and IFN-gamma Signaling Genes across Development and in Parkinson's Disease. PLoS One 9, e115029, doi: 10.1371/journal.pone.0115029 PONE-D-14-46807 (2014).

61. Martins-de-Souza, D. et al. Prefrontal cortex shotgun proteome analysis reveals altered calcium homeostasis and immune system imbalance in schizophrenia. Eur Arch Psychiatry Clin Neurosci 259, 151-163, doi: 10.1007/s00406-008-0847-2 (2009).

62. Kekesi, K. A. et al. Altered functional protein networks in the prefrontal cortex and amygdala of victims of suicide. PLoS One 7, e50532, doi: 10.1371/journal.pone.0050532 PONE-D-11-03198 (2012).

63. Zhai, J. et al. Proteomic characterization of lipid raft proteins in amyotrophic lateral sclerosis mouse spinal cord. FEBS J 276, 3308-3323, doi: 10.1111/j.1742-4658.2009.07057.x EJB7057 (2009).

64. Mielenz, D. \& Gunn-Moore, F. Physiological and pathophysiological functions of Swiprosin-1/EFhd2 in the nervous system. Biochem J 473, 2429-2437, doi: 10.1042/BCJ20160168 BCJ20160168 (2016).

65. Liu, J. L. S. \& S. N. Motion sickness susceptibility of Rhesus Monkeys. Space Medicine \& Medical Engineering 6(3), 197-203 (1993).

66. Ossenkopp, K. P., Macrae, L. K., Bettin, M. A. \& Kavaliers, M. Body-rotation induced analgesia in male mice: effects of duration and type of rotation procedure. Brain research bulletin 21, 967-972 (1988).

67. Golding, J. F., Mueller, A. G. \& Gresty, M. A. A motion sickness maximum around the $0.2 \mathrm{~Hz}$ frequency range of horizontal translational oscillation. Aviat Space Environ Med 72, 188-192 (2001).

68. Lawther, A. \& Griffin, M. J. Prediction of the incidence of motion sickness from the magnitude, frequency, and duration of vertical oscillation. J Acoust Soc Am 82, 957-966 (1987).

69. Paxinos, G. F. K. B. J. The mouse brain in stereotaxic coordinates (Academic Press, 2001).

70. Chen, Y. et al. Identification of RKIP as an invasion suppressor protein in nasopharyngeal carcinoma by proteomic analysis. $J$ Proteome Res 7, 5254-5262, doi: 10.1021/pr800602c (2008).

71. Brechlin, P. et al. Cerebrospinal fluid-optimized two-dimensional difference gel electrophoresis (2-D DIGE) facilitates the differential diagnosis of Creutzfeldt-Jakob disease. Proteomics 8, 4357-4366, doi: 10.1002/pmic.200800375 (2008).

72. Yang, F. et al. miR-17-5p Promotes migration of human hepatocellular carcinoma cells through the $\mathrm{p} 38$ mitogen-activated protein kinase-heat shock protein 27 pathway. Hepatology 51, 1614-1623, doi: 10.1002/hep.23566 (2010).

73. Strucksberg, K. H., Tangavelou, K., Schroder, R. \& Clemen, C. S. Proteasomal activity in skeletal muscle: a matter of assay design, muscle type, and age. Anal Biochem 399, 225-229, doi: 10.1016/j.ab.2009.12.026 S0003-2697(09)00873-2 (2010).

\section{Acknowledgements}

We thank A. S. Verkman and M. M. Poo for helpful discussions. This work was supported by grants from the National Basic Research Program of China (Program 973, No. 2009CB521900) to D.F. Su; the National Natural Science Foundation of China (Nos 30971427, 81273504, 81473258) to L. Li; and the National Natural Science Foundation of China (No. 81402941), a grant from the Shanghai Municipal Commission of Health and Family Planning (No. 20144Y0204) and a grant from the Science and Technology Commission of Shanghai Municipality (No. 15140904600) to Z.B. Wang.

\section{Author Contributions}

Z.B.W., P.H., X.H.Y. and L.C.T. designed the experiments, cultivated the SMS and RMS mice and conducted the animal studies and Western blot analysis; X.H.Z. and H.L. conducted two-dimensional fluorescence difference gel electrophoresis; X.W., W.Y.L. and Z.Z.L. injected the lentiviruses into the VN of the mice and performed parts of the Western blot analysis; W.H.S. and T.H.M. generated the swiprosin-1 knockout mice and offered advice on project planning; Y.L., F.W. and J.G.C. executed the electrophysiological study and offered advice on project planning; L.L., D.F.S. and Z.B.W. supervised the project and wrote the manuscript.

\section{Additional Information}

Supplementary information accompanies this paper at http://www.nature.com/srep

Competing financial interests: The authors declare no competing financial interests.

How to cite this article: Wang, Z.-B. et al. Low level of swiprosin-1/EFhd2 in vestibular nuclei of spontaneously hypersensitive motion sickness mice. Sci. Rep. 7, 40986; doi: 10.1038/srep40986 (2017).

Publisher's note: Springer Nature remains neutral with regard to jurisdictional claims in published maps and institutional affiliations. 
(c) (i) This work is licensed under a Creative Commons Attribution 4.0 International License. The images or other third party material in this article are included in the article's Creative Commons license, unless indicated otherwise in the credit line; if the material is not included under the Creative Commons license, users will need to obtain permission from the license holder to reproduce the material. To view a copy of this license, visit http://creativecommons.org/licenses/by/4.0/

(C) The Author(s) 2017 